\title{
Comparative study of Robinson's cytologial grading with Bloom Richardson's histologic grading for breast carcinoma
}

\author{
Vivek Kathed $^{1}$, Mohini Kucheria ${ }^{2 *}$ \\ ${ }^{1}$ Post Graduate Resident, ${ }^{2}$ Associate Professor, Dept. of Pathology, Sri Aurobindo Medical College \& Post Graduate Institute, \\ Indore, Madhya Pradesh, India \\ *Corresponding Author: Mohini Kucheria \\ Email: sanjaykucheria@gmail.com
}

\begin{abstract}
The study was conducted in the Department of Surgical Pathology, Sri Aurobindo Medical College \& PG Institute (SAMC\&PGI), Indore. Cytological study of breast lumps was done. All patients who were clinically suspected of having breast carcinoma were subjected to FNAC of breast lump under aseptic precautions after explaining the procedure, its potential complications and taking written consent. Local examination was done and details were recorded as per proforma. FNAC was performed by technique described by orell et all 2012.Slideswere stained by giemsa and PAP stain.

It is a useful parameter to be taken into consideration when selecting mode of therapy for breast carcinoma and to predict the tumor behavior. Cytological grading is especially useful in low resource settings, where core biopsies is not routinely performed for diagnosis of breast carcinoma. The cyto-prognostic grading helps in identifying fast growing tumors (Grade III\& II). Such tumors are more likely to respond to chemotherapy than the low grade, slow growing tumors, which are better suited to pretreatment with tamoxifen. Therefore, assessment of biological aggressiveness by cytological grading without removing the tumor is valuable approach.
\end{abstract}

Keywords: Robinson's Grade, Breast, Carcinoma \& Cytological Aspirates.

\section{Introduction}

Human breast carcinomas represent a group of diverse tumors that vary in their natural history and responsiveness to therapy. ${ }^{1}$ The biological characteristics of the breast cancer are used to estimate prognosis and select appropriate systemic therapy for patients. $^{2}$

Accurate diagnosis of breast cancer is made in $99 \%$ of cases by the combination of clinical examination, mammography and simple, noninvasive, cost-effective outpatient department procedure, fine-needle aspiration cytology (FNAC).

Histological grading of breast carcinoma using the Nottingham method described by Elston and Ellis (also called Elston's modified Bloom and Richardson method) is a widely accepted tumor grading system and has been found to have good prognostic correlations. ${ }^{3}$ In recent years, fine needle aspiration (FNA) cytology is increasingly being used for the pre-operative diagnosis of breast cancer. Attempts have been made to determine various prognostic parameters on FNA material for the management in a given case. ${ }^{4}$ The National Cancer Institute (NCI), Bethesda, sponsored conference had also recommended that tumor grading on FNA material should be incorporated in FNA reports for prognostication. It was also emphasised that the cytologic grading system on FNA specimens should correspond to the grading system used in the histologic material. Of the different cytologic grading methods corresponding to Elston's modified Bloom Richardson grading, the method described by Robinson et al. ${ }^{5}$ was found to be useful in grading breast carcinoma in FNA.

\section{Materials and Methods}

The study was conducted in the Department of Surgical Pathology, Sri Aurobindo Medical College \& PG Institute (SAMC\&PGI), Indore.

\section{Type of Study}

A cross-sectional study.

\section{Study Design}

The study included mastectomy specimens received from May 2016 to October 2017 (1year 6 months) and a prospective study from November 2017 to April 2019 (1 year 6 months).

\section{Inclusion criteria}

Patients of both genders cytologically diagnosed as having breast carcinomas and confirmed on histopathology were included in the study.

\section{Exclusion criteria}

1. All non-malignant lesions of the breast.

2. Cytologically proven breast carcinomas without histopathological confirmation. 


\section{Ethical Issues}

Approval from the ethical and research committee of Sri Aurobindo Medical College \& PG Institute was taken before conducting the research work (Letter of Approval is enclosed with the thesis)

\section{Data Collection and Methods}

1. For prospective study - All newly diagnosed cases of breast carcinomas proven on histopathologic study were included. Clinical details were taken from the patients and recorded.

2. Cytological and Histological slides were retrieved from Department of Surgical Pathology and clinical details were noted from hospital records.

\section{Methods of Evaluation}

1. Clinical parameters: Clinical details pertaining to age, gender, site of tumor, clinical signs \& symptoms were noted. Tumor size, location and ultrasound/Mammography findings were noted.

2. Cytological study of breast lumps was done. All patients who were clinically suspected of having breast carcinoma were subjected to FNAC of breast lump under aseptic precautions after explaining the procedure, its potential complications and taking written consent. Local examination was done and details were recorded as per proforma. FNAC was performed by following technique.

\section{Results}

Table 1: Age and Gender wise distribution of cases of Breast carcinoma

\begin{tabular}{|c|c|c|c|c|c|}
\hline \multirow{2}{*}{ S. No. } & $\begin{array}{c}\text { Age group } \\
\text { (in Yrs) }\end{array}$ & Fo. of Cases & Percentage \\
\cline { 2 - 6 } & $21-30$ & 4 & 0 & 4 & $3.57 \%$ \\
\hline 1. & $31-40$ & 26 & 0 & 26 & $23.22 \%$ \\
\hline 2. & $41-50$ & 34 & 0 & 34 & $30.36 \%$ \\
\hline 3. & $51-60$ & 27 & 0 & 27 & $24.10 \%$ \\
\hline 4. & $61-70$ & 17 & 1 & 18 & $16.07 \%$ \\
\hline 5. & $71-80$ & 1 & 1 & 2 & $1.79 \%$ \\
\hline 6. & $81-90$ & 1 & 0 & 1 & $0.89 \%$ \\
\hline 7. & Total & 110 & 2 & 112 & $100 \%$ \\
\hline
\end{tabular}

Table 2: Association of different tumor sizes with Robinson's cytological grades

\begin{tabular}{|c|c|c|c|c|}
\hline Tumor Size & CG I & CG II & CG III & Total \\
\hline$<2 \mathrm{~cm}$ & $5(35.71 \%)$ & $7(50 \%)$ & $2(14.29 \%)$ & 14 \\
\hline $2-5 \mathrm{~cm}$ & $20(28.98 \%)$ & $43(62.32 \%)$ & $6(8.70 \%)$ & 69 \\
\hline$>5 \mathrm{~cm}$ & $6(20.69 \%)$ & $18(62.07 \%)$ & $5(17.24 \%)$ & 29 \\
\hline Total & $31(27.68 \%)$ & $68(60.71 \%)$ & $13(11.61 \%)$ & 112 \\
\hline
\end{tabular}

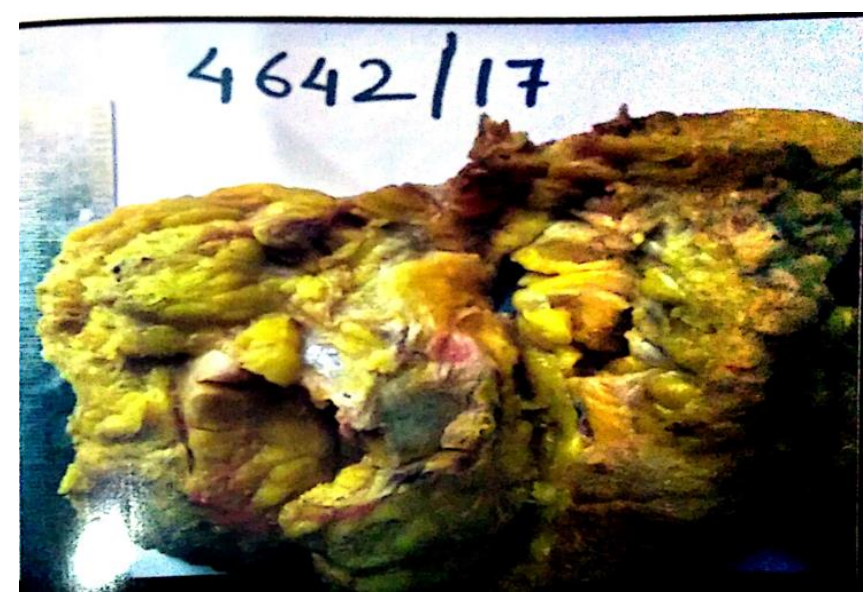

Fig. 1: Photograph showing cut section of infiltrating duct carcinoma of breast 
Table 3: Distribution of cases of breast cancer according to Robinson's cytological grade

\begin{tabular}{|c|c|c|c|}
\hline S. No. & Cytological Grade & No. of cases & Percentage of cases \\
\hline 1 & I & 31 & $27.68 \%$ \\
\hline 2 & II & 68 & $60.71 \%$ \\
\hline 3 & III & 13 & $11.61 \%$ \\
\hline & Total & $\mathbf{1 1 2}$ & $\mathbf{1 0 0} \%$ \\
\hline
\end{tabular}

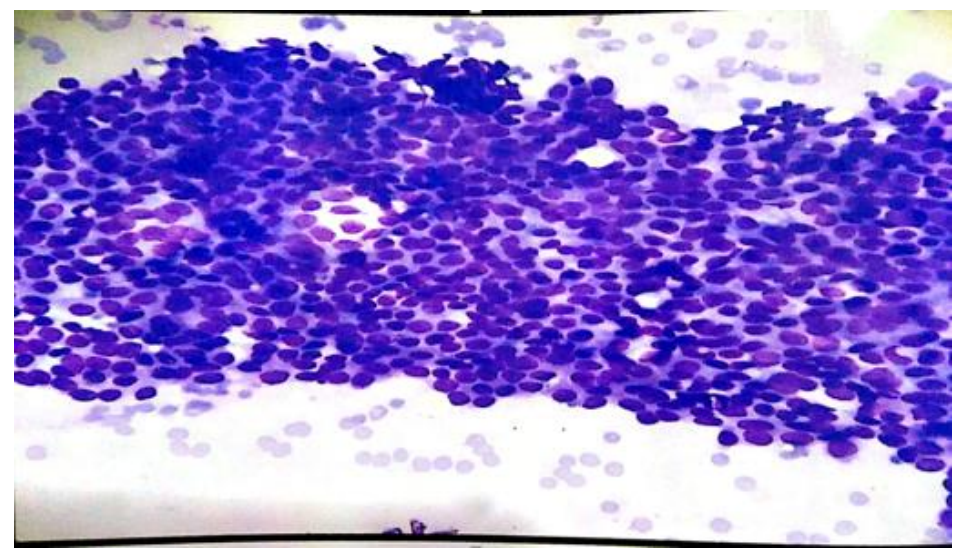

Fig. 2: Photomicrograph of aspirate showing infiltrating ductal carcinoma grade I(Giemsa100x)

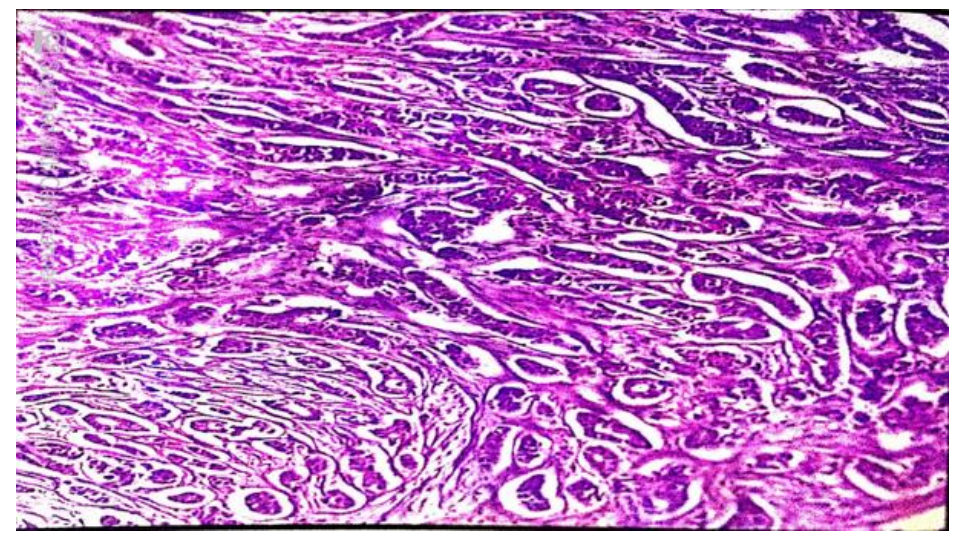

Fig. 3: Photo micrograph of infiltrating duct carcinoma Grade 1 (H\&E 100x)

\section{Discussion}

Jovicić-Milentijević M. et al. $(2005)^{6}$ graded breast carcinoma based on cytological features. FNA smears taken from 100 patients with invasive breast carcinoma were studied. The aspirates were stained by MayGrunwald-Giemsa and Papanicolaou technique. Cytological features were compared to the histological grade of breast carcinomas following excision, and the results were analyzed by the $\mathrm{x} 2$ test (the significance level was set to $\mathrm{p}<0.05$ ), as well as by the correlation coefficients (ri). Multivariate analysis was carried out by multiple correlation coefficients (Rij) for each pair of significant parameters. A scoring system based on these 6 parameters enabled the classification of tumors into low and high cytological grades which showed a close correlation with histological grade with $81 \%$ concordance. The best multiple correlations were found for the following pairs of cytological parameters: mitoses-apoptosis (0.603), mitoses-tubular formation (0.572), apoptosis-nuclear pleomorphism (0.550) and mitoses-nuclear pleomorphism (0.545).

Khan $\mathrm{N}$ et al. $(2009)^{7}$ has evaluated the cytologic and histological grading of 43 cases of IDC breast with specific reference to lymph node metastasis and its role in prognostication (employing Robinson's cytologic grading system and Elston's modification of BloomRichardson system, respectively). Statistical analysis was done employing ' $z$ ' test and $\chi 2$ test to compare the two-grading system. Multiple regression analysis was done to assess the significance of every cytologic and histologic parameter. With histologic grade taken as the standard, cytology was found to be comparable, for 
grading breast carcinoma (overall sensitivity $89.1 \%$, specificity $100 \%){ }^{8}$ Further comparison of the two grading systems by Z-test showed that difference between the cytologic and histologic grading was insignificant in all the three grades $(p>0.05)$. Of the six parameters studied, cell dissociation, nucleoli and chromatin pattern were the most influential features ( $\mathrm{p}$ $<0.001)$. The statistically significant difference $(\mathrm{p}<$ 0.001 ) was found in incidences of axillary lymph node metastatic rate in three cytologic grades $(15.4 \%$ in grade I vs. $83.3 \%$ in grade III) as well.

\section{Conclusion}

It is concluded from the present study that assigning a cytological grade in breast carcinoma aspirates is reproducible, corelates precisely with the histological grade and determines its aggressiveness. It is also useful in selecting the mode of therapy and to predict the tumour behavior without removing the tumour. Cytological grading is especially useful in low resource setting where core biopsy is not routinely performed for diagnosis. It helps in identifying fast growing tumours (Grade III and II) which are more likely to respond to chemotherapy than low grade, slow growing tumours which responds to Tamoxifen. The discordance between cytological and histological grades sometimes is due to variation in cytological features in different areas of tumour on histology because of limitations in sampling.

\section{Source of Funding}

None.

\section{Conflict of Interest}

None.

\section{References}

1. https:// www. who, int/ cancer/ prevention/ diagnosisscreening/ breast- cancer /en/(accessed).

2. http: // gco. iarc.fr/(accessed).

3. Masood S. Assessment of prognostic factor in breast FNA. Am J Clin Pathol 2000;113:s84-s96.
4. Ravikumar G, Rout P. comparison of cytological versus histopathological grading of invasive ductal carcinoma of breast with correlation of lymph node status - Middle East. J Cancer 2015;6:96-6.

5. Lingegowda, JB, Mudde Gowda, PH, Ramakantha CK, chandrasekar, HR. Cytohistological correlation of grading in breast carcinoma. Diagn cytopathol 2011;39:251-7.

6. American Cancer Society. Breast cancer Facts \&Figures 2017-2018. Atlanta: Am cancer Soc Inc 2017;1-5

7. Mckee GT, Tambouret RH, Finkelstein D. Fine-needle aspiration cytology of the breast: invasive VS, in situ carcinoma. Diagn Cytopathol 2001;25:73-7.

8. Fisher ER, Redmond C, Fisher B. Histologic grading of breast cancer. Pathol Annu 1980;15:239-51.

9. Bloom HJ. Richardson ww. Histological grading and prognosis in breast cancer; a study of 1409 cases of which 359 have been followed for 15 years. Br J Cancer 1957;11:359-77.

10. Dabbs DJ, Role of nuclear grading of breast carcinoma in fine needle aspiration specimens. Acta Cytol 1993;37:3616.

11. Robinson IA, Mckee G, Kissin MW. Typing and grading breast carcinoma on fine - needle aspiration: is this clinically useful information? Diagn Cytopathol 1995;13:260-5.

12. Latinovic L, Heinze $G$, Birner $P$, samonigg $H$, Hausmaninger H, Kubista E, et al. Porgnostic relevance of three histological grading methods in breast cancer. Int $J$ Oncol 2001;19:1271-7.

13. Khan N, Afroz N, Rana F, Khan MA. Role of cytologic grading in prognostication of invasive breast carcinoma. $J$ Cyto 2009;26(2):65-8.

14. Nandini NM, Rekha TS, Manjunath GV. Evaluatioon of Scoring System in cytological diagnosis and management of breast lesion with review of literature. Indian J Cancer 2011;48:240-5.

15. Koss LG. Diagnostic cytology and Its Histopathologic Bases, $3^{\text {rd }}$ ed; 1979, Philadelphia, JB Lippincott, P. 270,510 .

16. Koss LG, Woyke S, Olszewski W. Aspiration Biopsy; cytologic Interpretation and Histologic Bases, $2^{\text {nd }}$ ed New York, Igaku - Shoin, 1992.

17. Abati A, Mckee G. Grading of breast carcinoma in fineneedle aspiration cytology. Diagn Cytopathol 1998;19:1534.

How to cite: Kathed V, Kucheria M. Comparative study of Robinson's cytologial grading with Bloom Richardson's histologic grading for breast carcinoma. IP J Surg Allied Sci 2020;2(2):44-7. 